\title{
The influence of hub/tip ratio on hydraulic performance of an axial-flow impeller
}

\author{
Lijian Shi ${ }^{1}$, Fangping Tang ${ }^{1 *}$, Jiren Zhou ${ }^{1}$, Rongsheng Xie ${ }^{1}$, Lilong Qi ${ }^{1}$ \\ ${ }^{1}$ School of Hydraulic Energy and Power Engineering, Yangzhou University, Yangzhou225100, China
}

*Corresponding Author: tangfp@yzu.edu.cn

\begin{abstract}
To study the effects of hub/tip ratio on the hydraulic performance of axial-flow impeller, 4 impellers with different hub/tip ratio were optimally designed, the specific speed of these impellers are 743. The optimization design of axial-flow impeller used multidisciplinary optimization software iSIGHT, and Sequential Quadratic Programming (SQP), a gradient optimization algorithm, and meanwhile ensure a constant design flow and head, and change cascades dense degree of each airfoil section and size of airfoil placed corner to achieve optimal efficiency. Numerical simulation Software CFX was used for multidisciplinary analysis, N-S equation based on Reynolds-averaged and the standard k- $\varepsilon$ model were used in the optimization process to predict head, efficiency and cavitation margin value required of impeller. Performance curves of impellers with different hub/tip ratio were calculated by numerical simulation, and then the effects of hub/tip ratio to the hydraulic performance of axial-flow impellers with the same specific speed were analyzed. The results show that, the lager the hub/tip ratio, the higher the efficiency of impellers, and the worse the cavitation performance, but the effects on cavitation performance are more significant, the biggest difference of NPSH is $0.9 \mathrm{~m}$, in contrast, hub/tip ratio has less effects on efficiency, the highest difference between efficiency is only around $0.3 \%$. The larger the hub/tip ratio, the larger the slope of head performance curve; the higher the maximum head, the larger the range of head of saddle area, at the same time, with the increasing of hub/tip ratio, the range of efficient area will become narrower, and distribute to the side of a
\end{abstract}

small flow.

Keywords: iSIGHT, CFX, hub/tip ratio, axial-flow impeller

\section{Introduction}

The choice of hub/tip ratio is an important step in the design process of axial flow impeller. Hub/tip ratio is a very significant geometric design parameters, which is not only influenced by structural strength but also has an important effect on the internal flow field of impeller. Yang Jingjiang analyzes the effects of different hub/tip ratio on hydraulic performance of axial flow impeller theoretically ${ }^{(1)}$, and a conclusion is made that reducing the hub/tip ratio could reduce the loss of hydraulic friction, increase the flow area and improve the resistance to cavitation performance; however, reducing the hub/tip ratio excessively would increase the distortion of blade and disorder the liquid in off-design condition which results in a secondary flow in impeller outlet, decreases the efficiency of the impeller and narrows the high efficiency area. Guan Xingfan's statistical results about designed hub/tip ratio of axial-flow impeller and specific speed in Jiangsu university shows that different specific speed correspond to the recommended hub/tip ratio. ${ }^{(2)}$ The range of recommended hub/tip ratio under the different specific speed is given and different hub/tip ratio of the same impeller is studied in Wan Tao's paper ${ }^{(3)}$. It shows if hub ratio increases, then the lift drops and the efficiency rises. According to Wan Tao's research, hub/tip ratio and the design condition change at the same time, then it's not an accurate condition to discuss the effect on the performance of axial-flow impeller. 
Based on numerical optimization software iSIGHT and CFD numerical simulation software, this paper studies the influence of different hub/tip ratio on hydraulic performance of axial flow impeller under the same specific speed. The aim of optimization design is to achieve the optimal efficiency in the design conditions with the fixed specific speed of the impeller invariant. The influence of different hub/tip ratio on hydraulic performance of axial flow impeller will be researched under this constraint condition.

\section{Parametric Modeling}

Turbo-Grid is very convenient in rotating mechanical modeling and meshing and this paper will apply Turbo-Grid modeling to axial-flow impeller. In the process of designing the impeller, the blade should be divided into 10 airfoil sections along the radial direction. Based on the program written by FORTRAN, 10 sections of three-dimensional airfoil coordinates will be generated when basic design parameters of axial flow impeller are input. Then the file of coordinates will be imported into Turbo-Grid and Turbo-Grid will begin modeling and meshing for the axial flow. There are a lot design parameters of axial flow impeller, such as blade numbers, hub/tip ratio, cascades dense degree, airfoil thickness, blade angle, camber and so on. Blade numbers, hub ratio, cascades dense degree and blade angle have greater influence on the performance of impeller. Ensuring that blade numbers, airfoil and camber keep the same ,this paper will do research on the influence of different hub/tip ratio on the axial flow impeller under the same specific speed through changing cascades dense degree and blade angle.

\subsection{Cascades Dense Degree}

Cascades dense degree is an important parameter for the design of axial-flow impeller ${ }^{(4)}$, its value not only affects the efficiency and flow capacity of the impeller, but also determines the size of the impeller cavitation performance. When blade angle and a certain condition of coming flow are given, the cascades dense degree must satisfy the conditions of energy conversion. If cascade dense degree is too small, the relative speed of water flow will be faster, which would result in reducing the efficiency of the impeller and worsening the cavitation resistance; conversely, if cascades dense degree is too large, the loss of blade resistance and blade export rotational kinetic energy will increase which also would decrease the hydraulic efficiency of the impeller. Therefore, cascades dense degree is confirmed according to the highest hydraulic efficiency and cavitation resistance of the impeller.

During the design process of axial-flow impeller, it usually needs 10 data of the blade extension to the section of cascades dense degree when there are 10 airfoil sections. And the cascades dense degree of 10 sections usually use approximately blade equal intensity distribution from hub to tip. Therefore, only the tip and root times of cascades dense degree need to be decided. 10 sections of cascades dense degree are produced according to the tip and root times of cascades dense degree by FORTRAN. Then design variables will be reduced from 10 to 2 in order to improve the efficiency of blade optimization design. The geometry of axial flow pump blade will change successfully through changing the $\operatorname{tip}\left(a_{1}\right)$ and the root times $\left(a_{2}\right)$ of cascades dense degree.

\subsection{Angle of Blade}

The setting angle of blade airfoil also have a very important impact on performance of axial flow impeller. The blade airfoil of shroud is usually very thin, and almost straight so that blade attack angle is small and work capability is not strong. On the other hand, the blade airfoil of hub is relatively thicker, it has larger camber and blade attack angle, and the blade distortion will be severe. In the optimized design, angle of hub airfoil should be reduced and the outside angle of blade airfoil should be increased to reduce the blade distortion and improve working conditions of airfoil.As a result, this thus can improve the efficiency and expand the scope of the efficient area as well as cavitation resistance of the blade. ${ }^{(5)}$

The corresponding initial 10 sections of airfoil angle from hub to hub rim respectively are $11.3141^{\circ}, 17.6490^{\circ}$, $20.1023^{\circ}, 22.4793^{\circ}, 25.1727^{\circ}, 28.0223^{\circ}, 31.2910^{\circ}, 35.0863^{\circ}$, $39.6514^{\circ}$ and $45.3744^{\circ} .10$ design variables are so many that it directly affects the speed and efficiency of design optimization, so this paper expects to use a reasonable way to describe airfoil angle with less variables to control the changes. Through the analysis of 10 data, quadratic polynomial is used to fit 10 airfoil angle, its standard deviation is 0.999 and the error is small, a relative curve 
between airfoil angle and the relative radius section of the blade is as follows:

$$
\beta_{\mathrm{m}}=80.90-107.4 r+42.39 r^{2}
$$

Wherein, $\beta_{\mathrm{m}}$ stands for airfoil angle; $r$ stands for the relative radius of every section

For every kind of hub ratio, the relative radius of every section is certain; three values of quadratic polynomial can be changed by FORTRAN program to alter the angle of every airfoil section. $a_{3}, a_{4}$ and $a_{5}$ defining the above three values are used as design variables of the optimization design.

During the process of optimization design by iSIGHT software, five design variable values including cascades dense degree, root times of cascades dense degree and airfoil angle curve will be changed under different hub ratio within the designed flow of impeller and head unchanged. Other design parameters are chosen according to literatures.

\section{Numerical Simulation}

\subsection{Design Conditions}

The specific speed of model impeller in this paper is $n_{s}=743.8$, the designed flow is $Q=3201 / \mathrm{s}$, the head is $H=6.15 \mathrm{~m}$, and the speed is $n=1407 \mathrm{r} / \mathrm{min}$. Employing FORTRAN program for parametric modeling, Turbo-Grid for impeller 3-dimensional modeling and meshing, and CFX for preprocessing, calculating and reprocessing of numerical simulation by use of iSIGHT. The effects of different hub/tip ratios under the same specific speed on hydraulic performance of axial-flow impeller were analyzed; four different hub/tip ratios were calculated, they are $d=0.4,0.4333,0.4667$ and 0.5 .

\subsection{Independence of Grid}

CFX-TurboGrid is professional blade processing software in the field of rotating Machinery, which can create high quality impeller channel grids. By the using of grid template technologies, CFX-TurboGrid provides users with templates for a variety of blade machinery, from the axial flow, runoff to Francis, from compressors, turbines to a variety of pumps. Users can use it to generate efficient and high quality mesh models for the vast majority of blade machinery.
Under normal circumstances, the coarseness of the grid has a significant impact on the calculation results. Select rational grid coarseness can not only get a good calculation result to predict the performance of the pump, and sometimes also reduce the total number of nodes of the grid, saving computing time. Smaller node spacing will get more dense grid, in theory, can obtain a more accurate flow field, but doing so will result in a significant increase in the total number of grid cells and nodes, calculation amount will increase accordingly, the time required to calculate each step also significantly increased under the same calculation conditions.

In most cases, the more dense the mesh, the calculated value of the head, the power and efficiency will larger, but to a certain extent, these calculated values are stabilized. The grid-independent verification in this paper is based on the same calculation model (including turbulence model, boundary conditions, discrete methods, etc.), meshing way is also very similar, only because of the different distance of mesh nodes, the total number of mesh is not the same.

In this paper, numerical simulation software were employed by iSIGHT to study the effects of different hub/tip ratio on hydraulic performance of axial-flow impeller, the design conditions of different hub/tip ratio were the same by optimizing. Therefore, it is very important to make sure that each optimization analysis results are reliable and accurate, and the impeller grid independence test is very necessary. Turbo-Grid was used for modeling and meshing for the designed axial-flow impeller, analyzing the effects of different grid number on impeller efficiency, the results are shown in Figure 1.

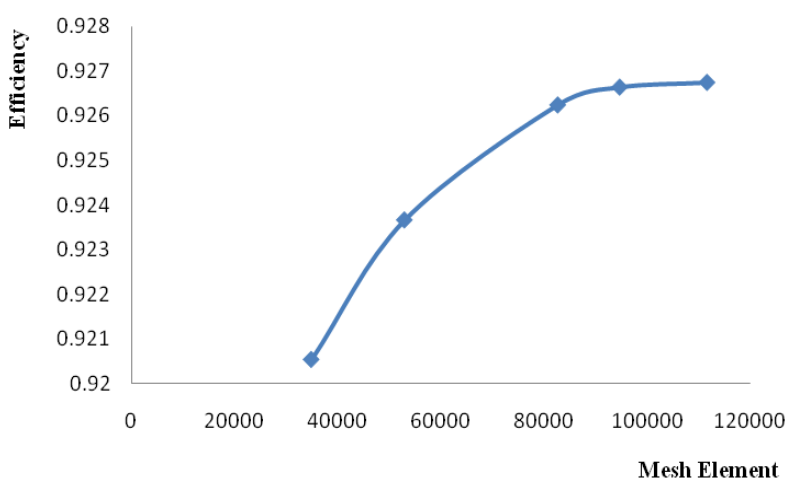

Fig.1. Relationship between grid number and efficiency

Figure 1 shows that, when the number of single-channel mesh around 100,000, further increase the number of grid had nearly no influence on the impeller efficiency, so, set 
the grid number at around 100,000 for calculating.

\subsection{Basic settings for Calculation}

This paper only calculated and analyzed impeller internal flow field, so take the impeller hub as center, take the inlet to the outlet area of the impeller as calculation area, what's more, the inlet velocity distribution of impeller is axially symmetric, ultimately selected a single impeller blade channel as calculating area for numerical simulation of the flow field, that will save time and improve computational efficiency. Take the standard k- $\varepsilon$ model as computational model, there are three main boundary conditions of impeller internal flow field need to deal with, they are the inlet boundary, outlet boundary, and wall boundary. As can be seen from the study of axial-flow pump outside parameters, The head and shaft power of axial-flow impeller can be predicted mainly by the given flow points, and then the efficiency of axial-flow pump impeller can be calculated. Therefore, the impeller inlet boundary conditions are set to total pressure, which is set to a standard atmospheric pressure; Outlet boundary conditions are set to mass flow rate, single flow channel is set to $80 \mathrm{~kg} / \mathrm{s}$ and axial feed flow; Wall boundary use no slip wall boundary conditions, and no leaf area of the wall boundary use periodic boundary conditions. ${ }^{(6-7)}$

\section{Optimization and Analysis of an Axial-flow Impeller}

\subsection{Optimization Algorithms}

Optimization of axial-flow impeller is a serial process, and the optimization model is a constrained nonlinear model. Gradient optimization algorithm is the ideal way to solve this kind of problems, so, this paper used Sequential Quadratic Programming (NLPQL) under gradient optimization for optimization, which is recognized as one of the best non-linear programming algorithms. The core of NLPQL is Sequential Quadratic Programming (SQP), it will expand the target function as second-order Taylor series, and constraints will be linearized, get the next design point by solving quadratic programming. SQP has a good global convergence and superlinear convergence properties, convergence speed is fast, fewer iterations required for solving process, and SQP has a strong ability to search along the boundary constraints, it's very suitable for solving the designed optimization problems with less optimization variables and few constraints in this paper.

\subsection{Establishment of the Optimization Model}

The purpose of optimization is to search for the optimal values of design parameters within the scope of the design variables, and finally meet the expectations of the objective function under the constraints. In this paper, the optimization problem of axial-flow impeller is defined as, when at the same hub/tip ratio, the constraint head is $6.15 \mathrm{~m}$, and cavitation performance meet certain requirements, changing the value of design variables to make the highest efficiency of impeller. The initial value of design variables is $a_{1}=0.82, a_{2}=1.2, a_{3}=80.9, a_{4}=-107.4, a_{5}=42.39$.

The optimization model as follows:

Optimization objective function: $\max \eta(\mathrm{x})$

Design variables range $\left\{\begin{array}{l}0.75 \leq a_{1} \leq 0.85 \\ 1.2 \leq a_{2} \leq 1.4 \\ a_{l 3} \leq a_{3} \leq a_{u 3} \\ a_{l 4} \leq a_{4} \leq a_{u 4} \\ a_{l 5} \leq a_{5} \leq a_{u 5}\end{array}\right.$

Constraints $\left\{\begin{array}{l}H=6.15 \\ \text { NPSHre } \leq 6.0\end{array}\right.$

Design variables: $\mathrm{x}=\left\{a_{1}, a_{2}, a_{3}, a_{4}, a_{5}\right\}$

Where $\eta$ stands for efficiency, $a_{1}$ stands for blade tip cascades dense degree, $a_{2}$ stands for multiples of blade root cascades dense degree, $a_{3}, a_{4}, a_{5}$ stand for 3 coefficients of airfoil placed corner quadratic; NPSHre stands for the necessary NPSH. The value range of $a_{1}, a_{2}$ is determined according to reference (2), $a_{l}, a_{u}$ stand for the minimum and maximum values of variables, which will be different under different hub/tip ratio, but they should be as close as possible, in order to avoid severe leaf distortion.

\subsection{Establishment of Data Flow}

iSIGHT is a automation tool for simulation analysis of the optimization process that provides a visual simulation processes to build a flexible platform. Based on axial-flow impeller design optimization ideas, built automatic optimization framework shown in Figure 2. And design flow chart shown in Figure 3 


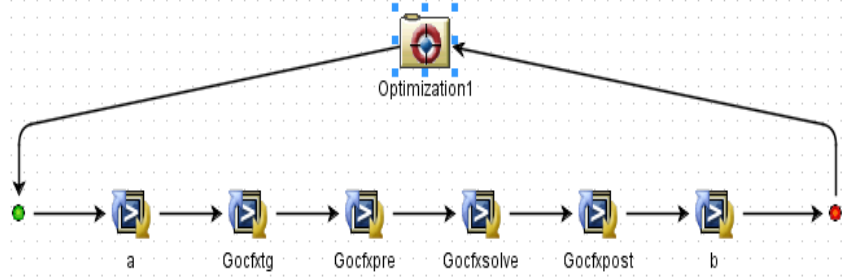

Fig.2 Optimization design framework of an axial-flow impeller

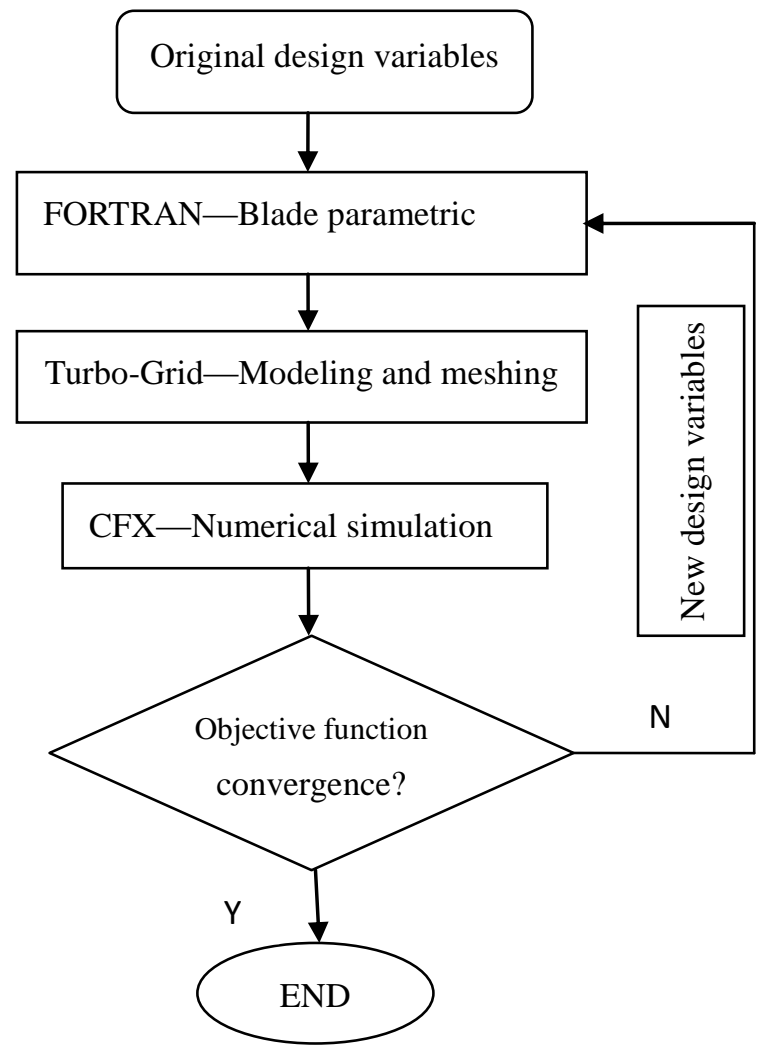

Fig.3 Flow chart of optimization design for an axial-flow impeller

Each hub/tip ratio needed this optimization iterative process. Block a generates a blade section data, Then employing the Turbo-Grid for axial-flow impeller for modeling and meshing, and use CFX to deal the mesh with pretreatment, calculation and post-processing. At last, block b will get the data to calculate and analyze before the output of head, efficiency and NPSHre values.

\subsection{Analysis of Optimization Results}

In the process of optimization, restrict the value of NPSHre, the formula shown below:

$$
N P S H \leftarrow e^{\nu_{0}{ }^{2}}+\lambda \frac{\omega_{0}{ }^{2}}{2 g}
$$

It is very difficult to get the value of NPSHre directly, this paper use the blade surface pressure to predict impeller's NPSHre value, the formula shown below:

$$
\text { NPSHre }=\frac{P_{0}}{\rho g}-\frac{P_{\min }}{\rho g}
$$

Wherein, $P_{\min }$ is the minimum surface pressure value back of the blade. According to the reference(12), take the pressure back of the blade where from hub span $=0.85$ spanwise airfoil section and about 10 percent from the blade inlet to calculate the NPSHre. $P_{0}$ is total pressure of inlet, and is set as an atmospheric pressure.

iSIGHT employing CFD software for optimizing the design of axial-flow impeller with different hub/tip ratio. The optimization design result as shown below in table 1 .

Table 1 Optimization Design Result

\begin{tabular}{|c|c|c|c|c|}
\hline Hub ratio & 0.4 & 0.4333 & 0.4667 & 0.5 \\
\hline$Q(1 / \mathrm{s})$ & 320 & 320 & 320 & 320 \\
\hline$H(\mathrm{~m})$ & 6.15 & 6.15 & 6.15 & 6.15 \\
\hline$a_{1}$ & 0.80375 & 0.75334 & 0.75788 & 0.75 \\
\hline$a_{2}$ & 1.200 & 1.3804 & 1.2008 & 1.3598 \\
\hline$a_{3}$ & 81.036 & 81.225 & 74.71 & 74.895 \\
\hline$a_{4}$ & -107.29 & -107.14 & -91.7333 & -91.581 \\
\hline$a_{5}$ & 42.488 & 42.499 & 34.744 & 34.876 \\
\hline Efficiency & 0.92862 & 0.93077 & 0.93046 & 0.93117 \\
\hline NPSHre & 5.0697 & 5.4505 & 5.6851 & 5.9459 \\
\hline
\end{tabular}

According to the design optimization results, under the same specific speed, the larger the hub/tip ratio, the higher the efficiency of the impeller, but little changed. With the hub/tip ratio larger, the necessary cavitation margin values increases, anti-cavitation performance of the impeller is getting worse, hub/tip ratio have more influence on cavitation performance. Under the design condition, get surface pressure of the impeller, shown in figure 4-5.

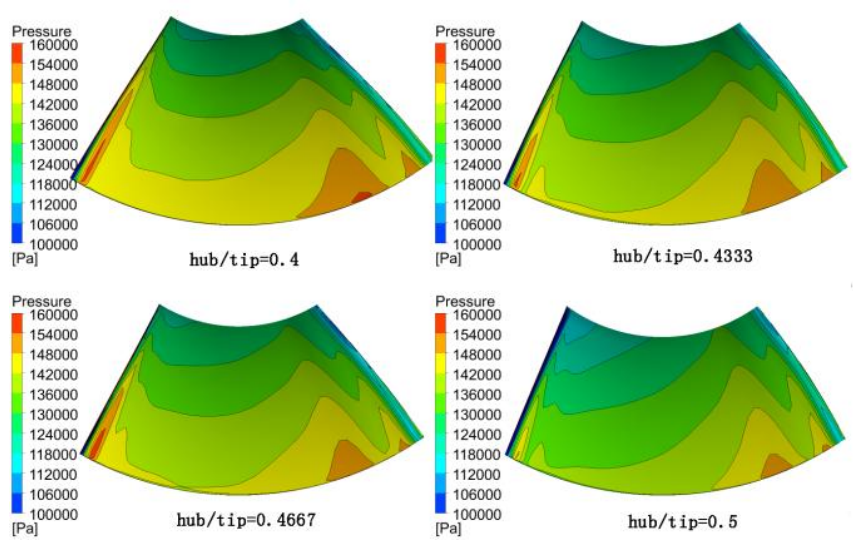

Fig.4 Surface pressure distribution of front blade 


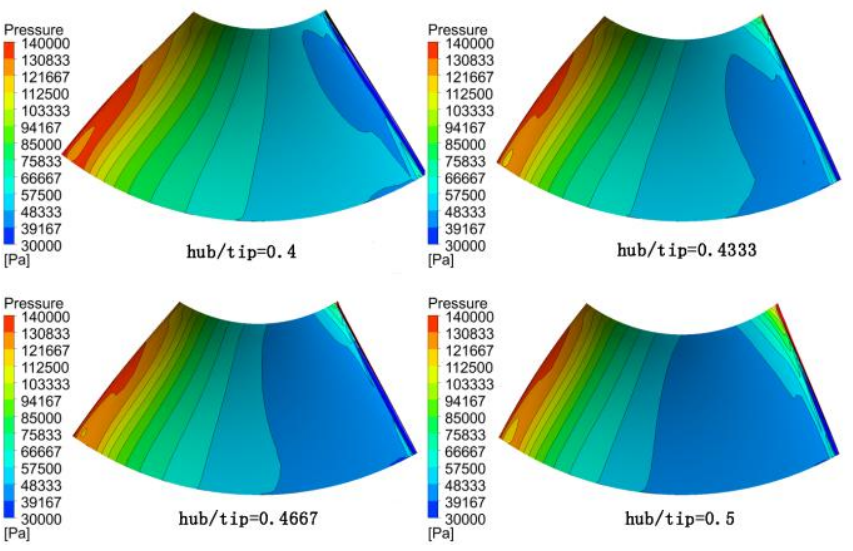

Fig.5 Surface pressure distribution of back blade

According to the front and back side pressure distribution of the impeller, under the design condition, the larger the hub/tip ratio, the smaller the front pressure distribution gradient, and the front pressure distribution is more reasonable; Back surface pressure distribution trend is consistent, but the larger the hub/tip ratio, the greater the range of the minimum back pressure, it has a larger cavitation range in the event of cavitation.

Based on impeller model with different hub/tip ratio optimized by iSIGHT, calculated impeller hydraulic performance in off-design condition by CFX. Get axial-flow impeller performance curve shown in figure 6-7.

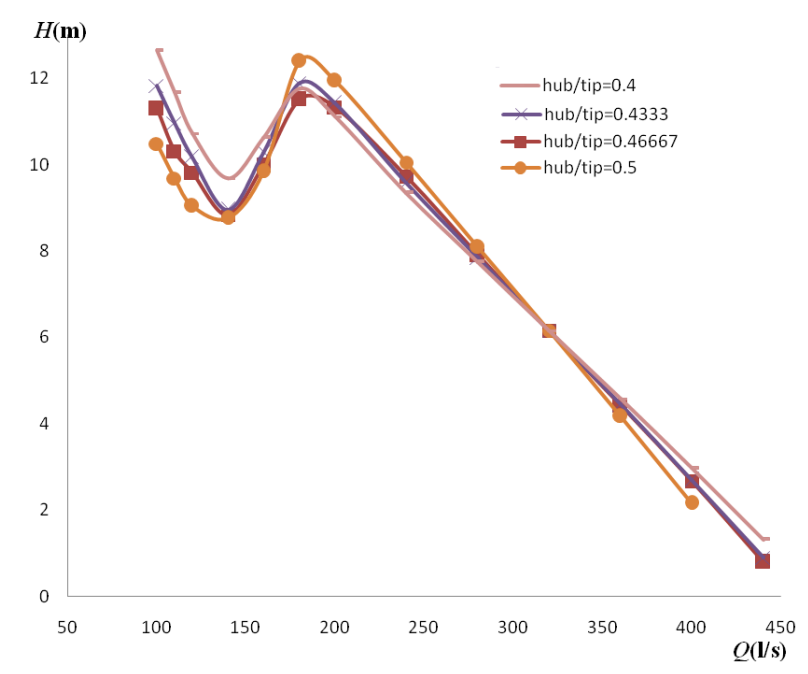

Fig.6 Flow-head curves between different hub/tip ratio

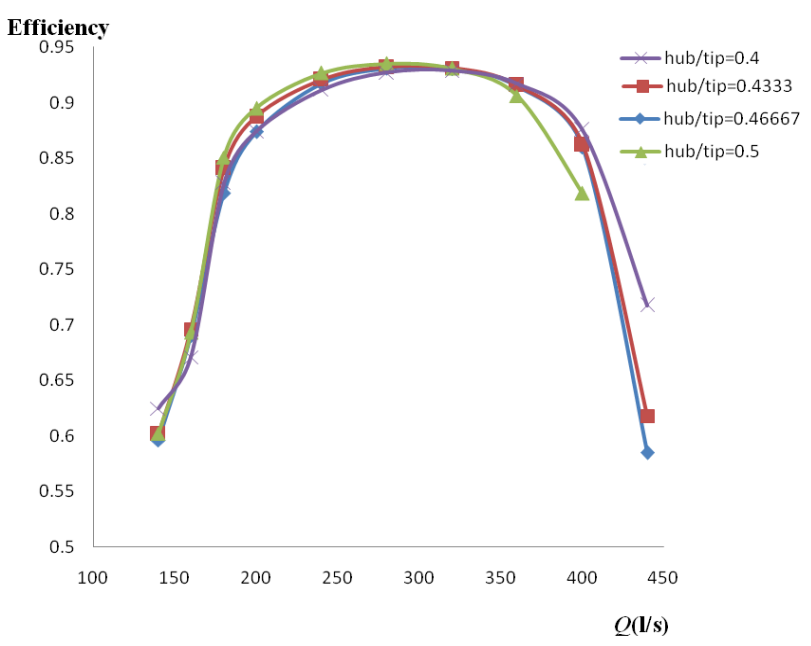

Fig.7 Flow-efficiency curves between different hub/tip ratio

According to flow-head curve of axial-flow impeller, near the design condition, flow-head curve is basically matched, and it changes more under off the design condition. Along with the increase of hub/tip ratio, flow-head curve slope becomes larger, in other words, flow-head curve rotates clockwise around the design point. At the same time, it can be seen, the head range in unstable operation area(saddle area)of the axial-flow impeller is wider as the hub ratio is bigger, saddle area is more obvious. For the flow-head curve of axial-flow impeller, high efficiency point is basically consistent. Along with the increase of hub/tip ratio, the high efficient area range of axial-flow slightly offsets to the small flow area. At the same time, the efficiency changes more obvious in the large flow area. The efficiency falls faster as the hub/tip ratio is bigger.

\section{Conclusion}

Researched the influence on axial-low impeller hydraulic performance of different hub/tip ratio by numerical optimization and numerical simulation technology, the following conclusion can be got:

(1) In the design condition, along with the increase of hub/tip ratio, the efficiency is higher, but cavitation performance is more poor and affected more obvious.

(2) Along with the increase of hub ratio, flow-head curve slope becomes larger, the maximum head is higher, the head range in saddle area is wider.

(3) Along with the reduce of hub ratio, the high 
efficient area range is more wide and offsets to the large flow area.

(4) In the frequently used condition when running head is lower than the design head, the small hub/tip ratio is more suitable; on the contrary, in the frequently used condition when running head is higher than the design head, the big hub/tip ratio is more suitable. Thus, the actual used condition of pump should be considered while selecting the hub/tip ratio.

\section{References}

(1) Yang Jingjiang : "Studies on Hydraulic Design Method and Numerical Simulation of Axial Flow Pump Model[D]”, Zhenjiang: Jiangsu University, 2008

(2) Guan Xingfan : "Axial flow pump and oblique flow pump hydraulic model test and engineering application[M]", Beijing: China Aerospace Press, 2008

(3) Wan Tao : "Parametric design of axial flow pump and Numerical simulation[D]", Wu Han: Huazhong University of Science \& Technology, 2013

(4) Wang Linghua : "Analysis of influence of blading density degree to characteristics of bidrectional tubulous pump[J]", Water Resources and Power, Vol. 21, No. 4, pp. 69-71.

(5) Tang Fangping, Zhou Jiren, Yuan Jiabo,et al : “CAD/ CAM of the hydraulic model for axial-flow pump $[\mathrm{J}]$ ”, Journal of Jiangsu Agricultural College, Vol. 19, No. 1, pp. 1-5, 1998

(6) Yang Zhengjun, Wang Fujun, Zhou Peijian : "Evaluation of subgrid-scale models in large-eddy simulations of turbulent flow in a centrifugal pump impeller[J]", Chinese Journal of Mechanical Engineering, Vol. 25, No. 5, pp. 911-918, 2012

(7) Ye Liang, Liu Zhongmin : "Design of implantable axial-flow blood pump and numerical studies on its pereormance $[\mathrm{J}]$ ", Journal of Hydrodynamics, Vol. 21, No. 4, pp. 445-452, 2009

(8) Zhao Min, Cui Weicheng : “Overview on research and application of multidisciplinary design optimization[J]", Ship Building of China, Vol. 48, No. 3, pp. 63-72, 2007
(9) Mao Huping : "Present situation and prospect of multidisciplinary design optimization technology $[\mathrm{J}]$ ", Mechanical Management and Development, Vol. 23, No. 5, pp. 54-56, 2008

(10) Fan Jiang, Zeng Weiwei, Wang Rongqiao,et al : "Optimization design of the turbine blade shroud based on iSIGHT software[J]", Journal of Aerospace Power, Vol. 26, No. 4, pp. 745-751, 2011

(11) Zhou Dada, Chen Guojin, Gong Youping : "Research of multidisciplinary optimization based on iSIGHT[J]", Mechanical\&Electrical Engineering Magazine, Vol. 26, No. 12, pp. 78-81, 2009

(12) Xie Dezheng : "Research on Automatic Design Optimization of Axial Flow Impeller[D]", Yangzhou: Yangzhou University, 2010 